\title{
DIALOGOS SOBRE PARTICIPAÇÃO: O QUE DIZEM OS JOVENS DA REGIÃO METROPOLITANA DE PORTO ALEGRE BRASIL
}

\begin{abstract}
SUELI SALVA*
RESUMO

NILDA STECANELA**

As reflexões apresentadas neste texto, tem por objetivo apresentar parte da análise dos resultados da pesquisa Juventude brasileira e democracia: participação, esferas e políticas públicas (IBASE/POLIS, 2005c) coordenada pelo IBASE e Instituto Polis, em parceria com universidades e organizações nãogovernamentais, e toma como referência os dados produzidos na Região Metropolitana de Porto Alegre (RMPA). ${ }^{1}$ A pesquisa desenvolvida em sete regiões metropolitanas do Brasil e no Distrito Federal teve como objetivo investigar processos participativos juvenis, levantando as formas, conteúdos e sentidos da participação de jovens de 15 a 24 anos, tendo em vista a importância desses sujeitos para a consolidação do processo de democratização da sociedade brasileira. Preocupou-se em estudar como os jovens participam, o que os instiga a participar e quais as significações/sentidos dessa participação juvenil nas esferas públicas e políticas. Revelou que os jovens desta pesquisa anunciam que as questões da sobrevivência são fundamentais para que possam realizar projetos de vida que incluam a participação e a luta pela construção de um Brasil melhor.
\end{abstract}

PALAVRAS CHAVE: JuVENTUde, PARTICIPAÇÃO, POLÍTICAS PÚBliCAS

* Doutoranda do programa de Pós-Graduação em Educação da Universidade Federal do Rio Grande do Sul. Professora da rede pública municipal de Porto Alegre, Brasil. E-Mail: susalva@cpovo.net.

** Doutoranda do programa de Pós-Graduação em Educação da Universidade Federal do Rio Grande do Sul. Professora da rede municipal de Caxias do Sul e do Departamento de Educação da Universidade de Caxias do Sul, Brasil. E-Mail: nildastecanela@terra.com.br.

1 Na Região Metropolitana de Porto Alegre, a pesquisa foi desenvolvida por um equipe de pesquisadores que teve como supervisor o professor Nilton Bueno Fischer e como assistentes de pesquisa as professoras Carmem Zeli Vargas, Nara Vieira Ramos, Nilda Stecanela e Sueli Salva. 


\section{RESUMEN \\ DIÁLOGOS SOBRE PARTICIPACIÓN: LO QUE DICEN LOS JÓVENES DE LA REGIÓN METROPOLITANA DE PORTO ALEGRE BRASIL}

El artículo tiene por objetivo el presentar parte del análisis de los resultados de la investigación «Juventud brasileña y democracia: participación, esferas y políticas públicas», coordinada por IBASE y el Instituto Polis, en asociación con universidades y ONG'S; y toma como referencia los antecedentes producidos en la Región Metropolitana de Porto Alegre. La investigación se desarrolló en siete regiones metropolitanas de Brasil y el Distrito Federal, y tuvo como objetivo el indagar en los procesos participativos juveniles, relevando las formas, contenidos y sentidos de la participación en jóvenes de 15 a 24 años de edad, teniendo en vista la importancia de esos sujetos para la consolidación del proceso de democratización de la sociedad brasileña. Se estudió cómo los jóvenes participan, lo que los motiva a participar y cuáles son las significaciones y sentidos de esa participación juvenil en las esferas públicas y políticas. La investigación reveló que los jóvenes considerados señalan que las cuestiones de la sobrevivencia son fundamentales para que puedan realizar proyectos de vida que incluyan la participación y la lucha por la construcción de un Brasil mejor.

Palabras clave: JuVentud, Participación, Políticas PÚblicas

\section{Abstract \\ INTERLOCUTATIONS ON PARTICIPATION: WHAT DO YOUNGSTERS FROM THE METROPOLITAN REGION OF PORTO ALEGRE, BRAZIL SAY}

This article is intended to submit part of the analysis of the results of the investigation «Brazilian Youth and Democracy: participation, spheres and public politics», which was coordinated by IBASE and the Polis Institute in addition to universities and ONG'S. It picks up as references the records produced in the Metropolitan Region of Porto Alegre. The investigation was developed in seven metropolitan regions of Brazil and the Federal Province with the purpose of inquiring over the juvenile participation processes regarding the participation, ways, contents and senses youngsters between 15 and 25 years old, keeping in mind the importance of these individuals form the consolidation of the democratization process of the brazilian society.

Some of the matters studied were: how do youngsters participate, their reasons for participating, which are the significations and senses of this juvenile participation in public and political spheres. The investigation discovered that the considered youngsters indicated that survival questions are of underlying importance in order to carry out life projects that include the participation and struggle for the construction of a better Brazil.

Key WORds: Youth, PARTicipation, PUblic POLITICS 
A PESQUISA «JUVENTUDE BRASILEIRA e democracia: participação, esferas e políticas públicas» aconteceu em duas etapas distintas, entre novembro de 2004 e maio de 2005. No primeiro momento - fase quantitativa - foram entrevistados oito mil jovens em nível nacional e mil jovens por região metropolitana, para a caracterização do perfil dos entrevistados e suas diferentes formas de participação. Nessa etapa, foram aplicados questionários formados por 46 questões, envolvendo os temas da educação, situação familiar, trabalho, mídia e acesso à cultura e formas de participação no campo cultural e político. $\mathrm{O}$ segundo momento - fase qualitativa - foi desenvolvido com base na metodologia Choice Work Dialogue Methodology — Grupos de Diálogo (GDS) - com orientação canadense. O principal pressuposto que orienta essa metodologia é «a busca de superação da lógica que domina as pesquisas de opinião no campo das políticas públicas, considerando que elas apenas constatam o posicionamento dos cidadãos» (Carrano et al., 2005), sem que eles tenham a oportunidade de refletir a respeito.

Os Grupos de Diálogo na RMPA envolveram noventa e oito jovens de diferentes idades, classes sociais, gênero e escolaridade, e aconteceram em cinco encontros de oito horas cada um. Os diálogos foram alimentados por informações que os jovens recebiam no início do encontro sobre os dados levantados na primeira fase da pesquisa, e sobre três possíveis caminhos participativos: o institucional, o voluntariado e o cultural.

As reflexões do dia de diálogo foram organizadas em várias modalidades, como forma de estimular a expressão da opinião dos jovens sobre cenários participativos em torno dos problemas vividos por eles na educação, trabalho e cultura e lazer. Os jovens foram desafiados a expressarem suas opiniões individuais no início do encontro e ao final, como forma de analisar as mudanças de posição a partir do diálogo instituído.

- Na opinião inicial, os jovens eram instigados a responder em uma palavra à pergunta: $\mathrm{O}$ que te preocupa no Brasil?

- Na opinião final, os jovens respondiam a duas questões: O que aconteceu de mais importante para você aqui hoje? Que mensagem você gostaria de deixar para as pessoas que tomam decisões no país?

Essas perguntas colocadas no início do encontro e no final eram respondidas individualmente. Após responderem à primeira pergunta, os jovens recebiam orientações e formavam pequenos grupos de diálogos. 
- Na parte da manhã, o diálogo foi orientado pela questão «Pensando na vida que você leva como jovem brasileiro(a), o que pode melhorar na educação, trabalho e nas atividades de cultura e lazer?».

- Na parte da tarde, os diálogos que aconteceram tiveram por base a pergunta: «Pensando no que vocês listaram pela manhã que deve melhorar na educação, trabalho e cultura no Brasil, como vocês estão dispostos a participar para que essas melhorias se tornem realidade?».

Um considerável banco de dados foi organizado a partir dos diálogos, com transcrição das narrativas dos jovens nos pequenos grupos e nas plenárias, tabulação das opiniões inicial e final, além da tabulação da pesquisa de opinião realizada na fase quantitativa e dos relatórios com análise dos dados das duas fases. Os dados produzidos nos GDS instigam olhares que podem ter múltiplas entradas. Neste texto, nos propomos a explicitar nossas concepções de diálogo e participação, entrelaçando as tendências, interdições, e potencialidades dos jovens sobre o tema central da pesquisa (participação) e seus eixos norteadores (educação, trabalho, cultura e lazer).

\section{GRUPOS DE DiÁlOGO: A CONCEPÇÃO DE DIÁLOGO COM A QUAL TRABALHAMOS}

A pesquisa teve como elemento central o diálogo, numa perspectiva de escuta que vai além de uma simples conversa, onde pessoas que não se conhecem se encontram para dialogar sobre um tema que não estava, a princípio, na pauta do seu dia-a-dia. O diálogo é uma conversa especial que agrega diferentes pontos de vista. Dialogar sem discutir, ou seja, defender uma opinião sem querer ganhar do outro, estimulando uma cultura democrática onde o diálogo pressupõe a escuta.

O princípio é que o «outro» tem partes da resposta e, por isso, procura pontos em comum na conversa, descobrindo novas possibilidades e formas de pensar. Portanto, esse diálogo, que não é a soma das opiniões individuais, apresenta-se simultaneamente como método de investigação e processo educativo ampliado. Para dialogar, é preciso escutar, silenciar, suportar o silêncio do outro, escutar o que o jovem diz quando aparentemente nada diz. É preciso «estar aberto para». Uma relação dialógica acontece a partir de uma abertura, de um desnudar-se diante do outro, de aceitar-se como ser em permanente for- 
mação, em permanente aprendizado. Na concepção de Freire, há uma razão ética para essa abertura, um fundamento político e uma referência pedagógica, pois «o sujeito que se abre ao mundo e aos outros inaugura com seu gesto a relação dialógica em que se confirma como inquietação e curiosidade, como inconclusão em permanente movimento na história» (Freire, 1997:153-154).

A metodologia colocada em prática nesta pesquisa estimula, em vários momentos, que os jovens falem a partir de seus contextos de vida, interagindo com os temas propostos (educação, trabalho, cultura/lazer), e com os caminhos participativos apresentados: Caminho um, «Eu me engajo e tenho uma bandeira de luta», ligado à participação política, cuja atuação está diretamente engajada aos partidos políticos, organizações estudantis, conselhos, ONG's e movimentos sociais. Caminho dois, «Eu sou voluntário e faço a diferença», possibilitando que os jovens voluntários ajudem a diminuir os problemas sociais, se envolvam em campanhas de doação de alimentos e outras ações voltadas à ajuda dos que mais necessitam. Caminho três, «Eu e meu grupo: nós damos o recado», possibilita que os jovens se organizem livremente e formem grupos culturais, religiosos e de comunicação, facilitando a agregação juvenil. Cada um dos caminhos serve como possibilidade de ação. O recurso utilizado para apresentar os caminhos participativos constituía-se de um caderno de trabalho, no qual cada caminho era apresentado de uma forma bastante didática. $\mathrm{O}$ objetivo era oferecer aos jovens elementos para que pudessem compreender cada caminho e analisar os prós e contras de cada escolha. Os caminhos participativos eram apresentados para que os jovens pudessem conhecer algumas formas de participação; eles tinham a liberdade de posicionar-se diante dos caminhos apresentados ou ainda criar outras possibilidades de participação, através da proposição de outros cenários participativos.

Portanto, a metodologia cria estratégias para que os jovens tenham o que falar. Conforme Freire,

Escutar é obviamente algo que vai mais além da possibilidade auditiva de cada um. Escutar, no sentido aqui discutida, significa a disponibilidade permanente por parte do sujeito que escuta para a abertura à fala do outro, ao gesto do outro, às diferenças do outro (Freire, 1997:135).

Esse «falar» do jovem se institui partindo do pressuposto de que há algo ainda para ser escutado e aprendido por nós, pertencentes ao 
mundo adulto. Nessa abertura ao nosso não saber, faz sentido o saber do outro. De acordo com Freire, esse saber, esse posicionamento que o jovem expressa, pode não coincidir com o nosso ponto de vista. Tampouco a intenção é fazer com que o jovem venha a pensar da mesma forma que pensamos, ou seja, que o jovem passe por um processo de convencimento a partir de nossas idéias. O que se deseja é aprender com as diferenças, como nos diz o autor, «é no respeito às diferenças entre mim e eles ou elas, na coerência entre o que faço e o que digo, que me encontro com eles ou com elas» (Freire, 1997:152).

É dessa forma que o sentido de «encontro» se amplia, significando mais que um simples reunir-se, tornando-se um «encontro com», para «aprender com». Essa postura pode nos trazer mais segurança, pois, ainda na perspectiva de Freire, a «segurança se alicerça no saber confirmado pela própria experiência de que, se minha inconclusão, de que sou consciente, atesta, de um lado minha ignorância, me abre, de outro, o caminho para conhecer» (Freire, 1997:153).

Melucci amplia essa idéia, a qual transpomos para o desafio na análise dos dados, pois segundo ele, «se partirmos de proposiçõs totalizantes, ao invés de uma proposição da qual se é consciente, então nenhum diálogo ou comunicação é possível» (Melucci, 1994:158). Para o autor, somente podemos assumir o ponto de vista de outra pessoa se conhecemos nossa própria posição no campo, incluindo aí as relações sociais, os discursos e as linguagens.

\section{A QUESTÃo da PARTICIPAÇÃO, TEMA CENTRAL dA PESQUiSA}

A «participação» foi o tema central da pesquisa «Juventude brasileira e democracia: esferas públicas e políticas», considerando a necessidade da escuta dos jovens como sujeitos ativos no processo, ainda inicial, de definição de políticas nacionais dirigidas aos setores juvenis da população brasileira. Nesse sentido, a pesquisa procurou estimular a participação e a democratização dos processos decisórios e de autonomia dos jovens como atores coletivos, possibilitando a compreensão de quais fatores ou elementos mobilizam seu engajamento.

Islas (2002), a partir de suas pesquisas realizadas no México, discute uma dimensão das políticas de juventude, relacionada à dificuldade de construir dinâmicas que facilitem a participação juvenil. Primeiro, porque ainda é considerada nos marcos de uma participação tradicional; segundo, porque pouco se sabe da vida dos jovens na cotidianidade. Cabe investigar a política da antipolítica juvenil, propon- 
do a questão: Para que e onde participar? O trabalho, a família e as instituições tradicionais (partidos, grêmios, sindicatos) transformam radicalmente a participação juvenil. Para o autor, a família tem se convertido mais numa relação do que numa instituição (posterga-se a união e a procriação, menos uniões formais, aumento dos divórcios, estar solteira como um estado permanente e a extensão da coabitação). $O$ trabalho apresenta-se, cada vez mais, como fator de insegurança na construção de um plano de vida. E os partidos não dizem nada aos jovens.

Para muitos, esse contexto se traduz em apatia, desinteresse e individualismo. Talvez devêssemos 'cambiar la mirada' para pensar de maneira diferente. De acordo com Serna (1997), esse outro olhar para a participação juvenil se institui dentro de um novo paradigma. Esse novo paradigma não se volta sobre a eficácia das formas de participação, para a constituição dos jovens ou para as mudanças sociais, e sim questiona onde, para que, por que e como os jovens participam/participariam. Os quatro pontos que configuram as novas formas de participação envolvem primeiramente as novidades nas causas de mobilização como os movimentos de proteção ambiental, direitos sexuais, direitos humanos. Em segundo lugar, os jovens priorizam a ação imediata e o que está mais próximo com o objetivo de modificar o contexto social em que vivem. Em terceiro preocupam-se com o lugar que vão ocupar dentro de determinado grupo e por último preocupam-se com a horizontalidade nos processos de coordenação.

Em outros tempos, essa participação formal construía identidade, respondia a questões «morais» postas pela sociedade e produzia um sentir-se útil na sociedade, através da busca da transformação do mundo. Hoje, trata-se de questionar onde os jovens estão buscando esses significados. Cada vez mais, os jovens vêem-se obrigados a realizar seus planos de vida sem as referências tradicionais. No entanto, os indivíduos tomam consciência de sua individualidade a partir do olhar do outro, num processo intersubjetivo em que «eu sou para ti o tu que tu és para mim» (Melucci, 2004). Portanto, quando se fala em participação juvenil, é preciso investigar onde os jovens estão construindo os nexos emocionais, onde e como estão buscando esse reconhecimento intersubjetivo e onde eles estão tomando consciência de sua individualidade, pois nos fazemos no encontro com o outro.

As contribuições de Melucci (2001:102) sobre as linguagens juvenis a respeito dos conflitos «pós-industriais» também são importantes para compreender as formas de participação juvenil. Essas formas podem estar expressas nas linguagens truncadas, nos silêncios, na 
expressão das emoções. Dentro do sistema clássico de participação por delegação (representatividade) que se encontra nas organizações como sindicatos, partidos e mesmo dentro do aparelho de estado, essas linguagens (formas de expressão da cultura juvenil), não têm guarida, não têm reconhecimento. A pesquisa fez uma busca radical "pelo diálogo», pelo registro das narrativas juvenis, em suas mais diversas manifestações, em torno dos temas propostos e dos caminhos participativos apresentados para a reflexão.

\section{PARTICIPAÇÃO JUVENIL: TENDÊNCIAS, INTERDIÇÕES, POTENCIALIDADES}

Fazendo uma análise, em termos gerais, sobre as tendências, interdições e potencialidades de participação dos jovens da RMPA, podemos afirmar que o cenário que mais mobiliza os jovens para a participação é o voluntariado; o que teria o maior grau de rejeição ou interdição são os partidos políticos e a atitude dos políticos; e, por sua vez, a cultura e o lazer, seriam potencialidades que estariam latentes para serem desenvolvidas. Segundo um jovem participante de um dos Grupos de Diálogo realizado na RMPA:

O voluntariado é muito interessante porque o voluntariado vai direto pra fazer o que tem que ser feito, só que ele esquece de cobrar o que as autoridades têm que fazer.

Os jovens apresentaram o «caminho um»- «Eu me engajo e tenho uma bandeira de luta»— como importante para resolver problemas da alçada do poder público, tais como violência, segurança, salários, emprego, entre outros. Por outro lado, destacam o «caminho dois» — «Eu sou voluntário e faço a diferença»— como possibilidade de fazer algo frente ao descaso do governo e o «caminho três» — «Eu e meu grupo: nós damos o recado» - na perspectiva de consumidores de cultura. As narrativas dos jovens expressam o que segue:

Eu acho que tô chegando à conclusão que a gente precisa de um pouquinho de cada um dos caminhos. Lendo o caminho dois, eu acho que a gente tem muita coisa pra fazer. Talvez, na visão desse, seja mais fácil o voluntariado.

No caminho três a gente lida com a parte cultural. No caminho dois a gente tem a solidariedade. No caminho um é a política. 
Por outro lado, numa análise mais aprofundada das narrativas produzidas pelos jovens da RMPA nos cinco Grupos de Diálogo realizados, podemos agrupar as suas tendências participativas em quatro idéias:

A primeira é a tendência de não dar crédito especial a nenhum caminho participativo isoladamente, mas uma escolha pelos três caminhos a partir do tipo de problema, através de uma combinação diversa entre eles.

Bom todos os grupos optaram por um quarto caminho, né? E esse quarto caminho inclui os três caminhos que foram oferecidos, né? Todos são, tem algum benefício, todos ajudam, né, a construir assim, uma educação melhor e um país mais democrático. Enfim, então isso foi assim, né, nos três, nos três grupos, optaram por esse quarto caminho (depoimento de um jovem da RMPA).

A segunda tendência revela descrédito na política, mas não no governo, apontando o que é de responsabilidade do Estado e o que os jovens precisam fazer, ou seja, reconhecem sua parte na construção do «Brasil que queremos»:

Os políticos prometem um monte de coisas, mas quando chegam lá não fazem nada, a culpa também é nossa porque é a gente que elege eles.

Eu acho que, as grandes revoluções que tiveram, leis e tudo, isso tudo do povo saindo na rua e lutando, e greve, e ficar de braço cruzado e esperar por político não adianta. Tem que sair na rua tem que juntar, eu sou um, eu sou socialista e eu tento passar essa mensagem para todo mundo.

Uma terceira tendência aponta a crença no voluntariado que não se resume, somente, ao entendimento do senso comum. É possível observar que o voluntariado assume, para estes jovens, sentidos diversos como o aprender com a troca, o ter um reconhecimento/visibilidade e a possibilidade de efetivar uma forma de ajuda concreta. Conforme narrativas dos jovens da RMPA:

Essa é a idéia do voluntariado, é tu começar ali pequenino, uma idéia, e aquilo vai aumentando, aumentando, a ponto que o governo vai respeitar a tua idéia, porque vocês são grandes. Acho que é essa a idéia, não adianta só tu cruzar os braços, ou juntar 50 mil pessoas numa praça e o governo vai ouvir, às vezes não ouve. 
Não é só no poder que conseguimos a transformação, mas também com os voluntários, que podem atingir aquilo que pensamos. Se o poder até agora não conseguiu, os voluntários podem conseguir ajudar as pessoas.

E, por último, há uma forte tendência, centrada no acesso à cultura mais como consumidores do que produtores:

Eu, por exemplo, gosto de sair, ir ao cinema, dançar. Tem gente que gosta de andar de bicicleta, de skate. Pode ser até escola aberta nos finais de semana, porque tem muitos bairros que não tem raça, quadra, mais para os guri né, porque as meninas não gostam de bola.

Refletindo sobre essas quatro idéias, aliadas às experiências com a metodologia dos Grupos de Diálogo e a análise das narrativas neles produzidas, é possível concluir que o movimento argumentativo dos jovens é pendular. Denunciam, culpam, apontam, responsabilizam, mas reconhecem sua parcela de responsabilidade na solução dos problemas. Essa é uma atitude interessante que rompe com representações dos jovens como alienados e desinteressados. Os estudos sobre juventude têm mostrado que os jovens querem ser ouvidos e têm o que dizer, usando linguagens diversas.

As críticas que fazem aos políticos e um certo «esquecimento» da participação via sindicato e partido podem estar associadas às reflexões de Mische (1997), quando comenta que os jovens viveram as crises e escândalos dos governos civis, sofreram a ansiedade da inflação e recessão econômica que sufocou muitas de suas aspirações. Tudo isso contribuiu para um ceticismo em relação à participação política. As redes interativas dos jovens se diversificaram a partir dos anos 90, com grande dispersão das identidades e projetos.

Hoje é preciso indagar sobre a existência de novas maneiras de articular projetos pessoais e coletivos, talvez sem grande escala utópica das décadas passadas. A emergência de várias formas contestadoras de expressão cultural, as manifestações pontuais dos jovens e, recentemente, a atuação dos jovens em ONG'S apontam para novas possibilidades de participação. A afirmação, por exemplo, da cultura afro-brasileira nos coletivos juvenis traz uma importante contribuição para a educação, reconhecendo que a democracia se constrói com a cidadania para todos.

É preciso, porém, romper com a idéia de que nos anos 60 e 70 as mobilizações juvenis eram mais políticas e nos anos 80 e 90 eram mais culturais. A cultura como modo de ser e estar no mundo envolve 
participação política. Hoje há formas de participação social mais visíveis e outras diferentes das que eram registradas nas décadas anteriores.

Nesse aspecto, a pesquisa apontou um rumo diferente entre os jovens entrevistados, pois o caminho da cultura ficou «na sombra», ou seja, uma ausência do caminho três como estratégia de mobilização e participação. Porém, nas falas dos jovens e nas sínteses das semelhanças, a cultura apareceu como possibilidade para viabilizar determinadas situações que apontem as responsabilidades do governo. $\mathrm{Na}$ discussão sobre o «acesso» aos bens culturais, os jovens da RMPA realizaram uma dupla entrada em torno da «cultura»: de um lado como bem (na forma de show, evento, espetáculo, etc.) a ser usufruído e, de outro, a clara indicação que cabe ao estado ser o provedor da segurança, zelar pela não-violência, pelos preços acessíveis e pela descentralização dos eventos. Em alguns diálogos realizados nos pequenos grupos observou-se que a possibilidade de acesso aos bens culturais se efetiva através da escola.

Os diálogos mostraram que a escolha de um único caminho se mostra insuficiente. Os jovens escolheram aproximações entre os caminhos participativos em função dos temas e atores neles implícitos e, num segundo momento, fizeram a conexão com os demais caminhos. Houve uma forte tendência no voluntariado como caminho participativo, talvez na perspectiva de «ver» o que é possível e próximo. O próximo está associado com o imediato, ou seja, não esperar só por iniciativas governamentais. Pode-se dizer que há um desejo de participação, sempre latente, independente do «como participar». Conforme a conjuntura esse desejo de participação se direciona para questões mais pontuais e de busca de sentido da ação juvenil. Um pouco do que Melucci aponta, que a «agregação não é possível se não existe uma certa coincidência entre os objetivos coletivos e as necessidades afetivas, comunicativas e de solidariedade dos membros» (Melucci, 2001:98).

Leslie Serna (1997) traz uma reflexão sobre a participação juvenil no contexto do desemprego, da industria cultural e da inserção dos jovens no narcotráfico, apontando para um novo paradigma da participação juvenil, pautado por quatro elementos: a novidade das causas de mobilização, a priorização da ação imediata, a importância do indivíduo na organização do movimento (o indivíduo é o centro das práticas e o grupo de pares não é mais um fim em si mesmo) e a ênfase na horizontalidade dos processos de coordenação.

Nas palavras de Serna, «la participacíon juvenil se expresa hoy dia em pequeños colectivos y grupos y, muy claramente en acciones 
diversas em las que se participa de maneira individual» (Serna, 1997:49). Os jovens não querem perder sua individualidade na massa e estabelecem formas de participação social pouco ou nada relacionadas com a via tradicional, o que lhes permite uma grande flexibilidade de atuação em campanhas específicas, em redes de informação e em ações concretas. De acordo com a pesquisa de opinião realizada na primeira fase na RMPA, a participação dos jovens se expressou através de três campos distintos: esportiva, musical e religiosa; estudantil, comunicação, partidos e políticos e melhoria das condições no bairro; e meio ambiente, trabalhos voluntários e trabalhos de escola. Isso coincidiu com a escolha/criação de um quarto caminho, que faz diferentes combinações entre os três caminhos participativos inicialmente apresentados.

As falas dos jovens sobre voluntariado apontam para um entendimento desse tema como troca, como forma de começar por pequenas coisas, tornar-se grande e ser ouvido, como responsabilidade no sentido de cada um fazer a sua parte e como forma de manifestação e denúncia. Obviamente, as manifestações dos jovens em defesa de tais idéias, em muitas ocasiões, foram polêmicas, gerando pontos de concordância e discordância. Mas é possível dizer que foi sempre muito forte a defesa do voluntariado, a partir desses enfoques. Sobre a ação voluntária, Melucci anuncia que:

O emergir de formas de ação voluntária nas sociedades complexas, sobretudo no campo da saúde e da assistência, verificou-se num clima de crise crescente dos modelos de welfare, quando já o seu declínio era visível nas sociedades que antes os tinham introduzido. [...] $\mathrm{O}$ fenômeno contém, no seu interior, realidades heterogêneas dificilmente unificáveis sob uma única categoria. É necessário, portanto, reconhecer que nos movemos no terreno da ação coletiva, não no terreno do Estado ou do mercado, nem mesmo da solidariedade privada, ou da troca interindividual, ainda que todas essas dimensões entrem para definir os limites do campo empírico (Melucci, 2001:116).

Com Melucci podemos ampliar a reflexão, considerando que os jovens são uma espécie de paradigma dos problemas mais cruciais da sociedade atual, definido na tensão entre expansão das oportunidades e a efetiva capacidade de ação. Há um crescimento dos estímulos e oportunidades para a ação individual, pois hoje podemos nos dirigir ao mundo inteiro em uma interação planetária. Nesse contexto, a experiência é cada vez menos um dado e cada vez mais uma realidade 
construída mediante as representações e relações. Cada um é chamado a escolher, fazendo com que a incerteza faça parte da ação.

Diante da ampliação das possibilidades, o que fazer? O que escolher? O imperativo da incerteza impõe a necessidade da escolha. Melucci chama de paradoxo da escolha: de um lado, a ampliação do espaço de autonomia individual que expressa na escolha. Mas, de outro, a impossibilidade de não escolher. Isso não significa dizer que «todos escolhem tudo sempre». A ampliação de possibilidades acontece num contexto perverso, pois os jovens pobres, além de privados da materialidade do trabalho, defrontam-se com a desigualdade no acesso aos recursos para sua auto-realização, desprovidos do direito à juventude.

Hoje os estudos sobre juventude buscam romper, tanto com a visão de classe média estudantil, como com a tendência de tratar o segmento juvenil como problema social, ou seja, jovens em situação de risco. O desafio é pensá-los como sujeitos de direito, examinando os elementos da condição juvenil contemporânea e quais direitos dela emergem.

\section{DIALOGANDO COM OS DADOS SOBRE A CULTURA, A EDUCAÇÃO E O TRABALHO}

As atividades culturais e de lazer têm uma importância significativa na vida dos jovens, pois elas permitem que os mesmos adquiram maior visibilidade, facilitem o processo de identização, ${ }^{2}$ (Melucci, 2004) e reduzam a tensão entre o tempo interno e o tempo social. Essas hipóteses podem ser analisadas por meio de duas tendências controversas.

A primeira tende a olhar as práticas culturais como homogêneas, pois estariam orientadas por idéias que as considera específicas e «exclusivas de uma fase da vida» (Pais). Nessa tendência, eleva-se a idéia de que a juventude se caracteriza pela homogeneidade.

A outra tendência toma as práticas juvenis como normativamente marginais, ou seja, são aquelas que se contrapõem à ordem dominante, e nesse caso seriam as práticas das gerações adultas. As práticas exercidas pelos jovens seriam caracterizadas como disfuncionais, tomadas de certa passividade, marginais e, por vezes, até mesmo sem regras ou normas (Pais). Para contrariar essa tendência, basta considerar que,

2 A expressão «identização» utilizada por Melucci (2004) tem o objetivo de expressar o caráter processual, contínuo da constituição da identidade realizada por meio de ações constantes. 
embora os jovens incorporem elementos de outras culturas, em alguma medida podem estar produzindo suas próprias normas e regras.

O segundo ângulo que orienta a tendência da juventude em relação às atividades culturais e de lazer se dão, principalmente, pela disponibilidade de tempo livre. Mas isso também requer uma reflexão, pois para a juventude o tempo livre já não se caracteriza mais como uma promessa, mas como uma realidade. Entretanto, isso não significa a democratização do lazer, é antes uma «precarização social empobrecida, material e espiritual para a gigantesca parcela da humanidade» (Carrano, 2003:136). O tempo livre que poderia abrir a possibilidade de participação em grupos culturais e atividades de lazer é impossibilitado pela falta de recursos.

Em relação aos dados da pesquisa, os jovens demonstram a tendência de que são mais consumidores culturais do que produtores. Olhando analiticamente para essa perspectiva, podemos sinalizar que os jovens estariam atendendo aos apelos da mídia e a partir dela incorporam estilos de roupas e gostos musicais. Entretanto, temos que levar em consideração que a economia capitalista tem feito grandes investimentos com o objetivo de atingir essa fatia considerável para o mercado do consumo. O jovem se tornou o boom do mercado (Salva, 2006). Observa-se também que os jovens têm consciência de que não podem se restringir a essa forma de participação, pois a cultura pode levar à inserção na política. Segundo um jovem da RMPA:

Tu tá no grupo de jovem, tanto dá pra fazer uma atividade política, como solidária, como fazê cultura! No grupo de jovens que eu faço parte, a gente faz isso, a gente faz teatro, a Via Sacra, por exemplo, e aí, a gente foi apresentá na praça e aí a gente faz política!

Os jovens associam a presença do estado com a oferta de lazer, sinalizando um possível caminho para a solução desse problema que os afeta atualmente. Dizem que há falta de patrocínio do governo ao esporte e à construção de pistas poliesportivas, por exemplo. Um menino negro diz que «tinha que ter pista de skate mais próxima de casa, porque o lazer está mais voltado para a burguesia». Afirmam ainda que o esporte afasta os jovens das drogas. Essas narrativas dos jovens podem relacionar-se à oferta de alternativas de lazer com a ocupação dos seus tempos livres. Mas levando em consideração a análise de Melucci (2004) em relação à importância da cultura, da arte, do mito e do jogo, talvez o esporte afaste os jovens das drogas não só porque 
está ocupando o seu tempo livre, mas porque esse pode ser um dos canais que reduzem a tensão entre o tempo interno e o tempo social. Para Melucci, o tempo interno é aquele do corpo, das emoções, dos sentimentos. Esse tempo é reversível, descontínuo e possibilita que tempos diversos possam coexistir. Ontem, hoje e amanhã, o meu tempo e o do outro podem viver simultaneamente. Já o tempo social é mensurável, contínuo, irreversível. O tempo social é uniforme e segundo o autor, «para cada tipo de evento existe uma cadência, um ritmo certo sobre o qual se fundem as expectativas e cuja conservação garante a ordem social» (Melucci, 2004:32).

Um canal que pode estar sendo utilizado pelos jovens da classe social D/E é a adesão aos grupos que lutam para as melhorias das condições de vida do bairro, uma vez que estes são os que mais se envolvem e as outras formas de redução de tensão se mostram ausentes.

Os dados em relação à participação na cultura apontam de modo geral que há um índice muito baixo de participação. Apenas 20,9\% dos jovens entrevistados fazem parte de algum grupo. Dentre esses, observa-se que a participação nessas atividades culturais é mais elevada entre as jovens, com mais presença da faixa etária dos 15 aos 17 anos, com aumento proporcional à escolaridade, ou seja, os jovens de mais escolaridade são os que mais participam em grupos, com um índice de 23,6\%. Destacam-se também os jovens das classes sociais A/B com um índice de $27,7 \%$, seguidos das classes sociais $\mathrm{D} / \mathrm{E}$ com $20,2 \%$, estudantes da escola privada com $26 \%$ e os que estão estudando com $27,8 \%$.

Em relação às manifestações culturais, especificamente sobre a participação em grupo artístico ou cultural (hiphop, rap, grafite, bandas, etc.), apenas 3,9\% ainda participa atualmente, sendo que $16,6 \%$ já participou e não participa mais. $O$ perfil do jovem que participa desse tipo de grupo envolve a maioria do sexo masculino, da faixa etária dos 15 aos 17 anos, da classe social A/B, solteiro e com escolaridade inferior, estudante da escola privada. Quando foram perguntados sobre os grupos em geral, as atividades mais citadas pelos jovens foram: esportivas com $40,2 \%$, música, teatro e dança com $31,9 \%$, religiosa com $23,9 \%$, estudantis com $12,0 \%$, comunicação $11,0 \%$, político partidário $7,2 \%$. Chamam à atenção as atividades que buscam melhoria para as condições de vida do bairro. Só 6,2\% participam; entretanto, entre esses, $17,5 \%$ são da classe social $\mathrm{D} / \mathrm{E}$, contra $5,1 \%$ da classe social $\mathrm{A} / \mathrm{B}$ e $2,5 \%$ da classe $\mathrm{C}$. 
De modo geral, esses dados apontam que os jovens mais pobres são os que menos freqüentam espaços de cultura e lazer. Cabe aqui uma interrogação. Se o índice mais elevado de desemprego está na classe social D/E, se estes são os que menos participam de atividades culturais, que oportunidades esses jovens dispõem para diminuir a tensão entre tempo interno e tempo social? Estariam criando outras formas de expressão dessa tensão, além do trabalho, da cultura e do lazer?

Em relação à educação, percebemos uma expansão nas oportunidades escolares para a população juvenil com um crescimento significativo do acesso à escola, especialmente na esfera pública, a partir da década de 1990. Esse dado se revela contraditório na pesquisa realiza$\mathrm{da}$, pois, dos mil jovens entrevistados na primeira fase da pesquisa, $58,7 \%$ não estão estudando. Segundo Stecanela (2006), isto demonstra que o direito universal à escolarização está longe de ser garantido, pois mais da metade dos jovens entrevistados está fora da escola, não usufruindo do direito à educação básica no tempo devido ou da continuidade nos estudos, através do ingresso no ensino superior.

Na palavra inicial dos jovens ao longo dos Grupos de Diálogo, a educação aparece em terceiro lugar, atrás das preocupações com a violência e com o desemprego. Os diálogos em torno desse tema tiveram o acento numa perspectiva escolar, sendo que pouco ou quase nada foi referido a alternativas ou espaços educativos. No contexto da modernidade, a escola ainda se faz cada vez mais presente na vida cotidiana dos jovens, pois é o lugar onde eles pasam mais tempo, quer em atividades formais, quer em atividades informais como é o caso da escola aberta aos finais de semana. Abrantes diz que os jovens não são simples usuários da escola, mas apropriam-se dela, atribuem-lhe sentidos e são transformados por ela (Abrantes, 2003 :93).

Segundo Stecanela (2006), a centralidade que a escola ocupa na vida dos jovens pode ser uma justificativa para a intensidade com que, em todos os Grupos de Diálogo, fizeram denúncias às suas péssimas condições, em termos de infra-estrutura, valorização e formação dos professores, organização curricular e metodologia.

Em relação ao trabalho, percebe-se que $55,6 \%$ não estão trabalhando. Quando esse índice é analisado por gênero, podemos perceber que $43,3 \%$ dos jovens do sexo masculino não estão trabalhando. Esse índice aumenta para $67,7 \%$ quando se trata do gênero feminino. Dos jovens que trabalham, 16,4\% não têm carteira assinada. O maior índice de desempregados encontra-se na faixa etária de 15 a 17 anos, com 75,0\%; de 18 a 20 anos, com 53,0\%, e de 21 a 24 anos, com 43,0\%. Em relação à 
classe social, os índices também se diferenciam. Da classe A/B, 53,3\% estão desempregados, da classe $\mathrm{C}, 52,7 \%$, e da classe $\mathrm{D} / \mathrm{E}, 64,6 \%$.

Os jovens apontam as limitadas oportunidades, a exigência de experiência e as diferenças salariais, tanto geracional quanto nas questões de gênero que existem no Brasil para a conquista do primeiro emprego. Esses aspectos, situados no contexto das alterações no mercado de trabalho nas últimas décadas, acentuaram a exclusão de parcela dos jovens, a partir do desassalariamento e trabalho informal, além do desemprego. Os jovens constituem a faixa da população economicamente ativa (PEA) mais atingida pelo desemprego. Acompanhando dados analisados por Spósito (2003), os índices de desemprego em 2001 chegaram a $12,1 \%$ para todas as faixas etárias, mas para os jovens de 15 a 19 anos foi de $27,3 \%$ e nas faixas etárias de 20 a 24 anos de $18,9 \%$.

\section{PARTICIPAÇÃO JUVENIL, UMA NOVA MIRADA}

José Machado Pais propõe que a categoria juventude seja compreendida a partir de sua contextualização histórico-cultural. Hoje, podemos dizer que os jovens são filhos da mudança, de uma ordem social marcada pelos desgastes dos discursos dominantes. Conforme o autor, assistimos a um processo de desinstitucionalização da vida social, não porque esteja em vias de extinção, mas por serem vias de mudança. Em outras palavras, a crise das instituições pode ou não ser de decadência, mas de re-institucionalização permanente.

Essa complexidade da realidade torna necessários novos rumos para os estudos sobre juventude. Hoje, um pouco mais libertas da razão instrumental, as pesquisas nas ciências sociais e humanas, buscam ouvir mais intensamente os jovens, considerados atores sociais. Porém, é necessário ampliar e institucionalizar canais de interlocução entre os jovens na discussão e formulação de políticas públicas.

A participação dos jovens tem ocupado o debate público que ganha força no Brasil, principalmente como possibilidade de avanço da democracia social e política, muito embora não haja nenhum fórum público que possa constituir-se num canalizador das demandas juvenis.

Helena Abramo considera que a preocupação com a participação dos jovens,

É marcada por certa ambigüidade: por um lado, existe uma percepção da importância da participação juvenil para o desenvolvimento democrático, 
que vem acompanhada de uma expectativa de seu incremento; por outro, impera uma certa visão negativa a respeito da participação existente e uma dificuldade de concretizar canais efetivos para a sua realização. Essa ambigüidade é acompanhada por uma dificuldade de estabelecimento de relações entre os atores e instituições sociais que dominam a cena pública (governamentais e não governamentais) e os atores coletivos juvenis (grupos, organizações, movimentos e «movidas» de jovens), ainda pouco visíveis e compreendidos como interlocutores válidos para lidar com as questões concernentes a eles.

A pesquisa «Juventude brasileira e democracia: participação, esferas e políticas públicas» buscou compreender a complexidade do cenário nacional acompanhando o debate em torno do tema das políticas públicas de juventude no Brasil e também a noção de como a «participação» se processa em suas diversas formas, ações e reflexões. Esse debate suscita a necessidade de que os jovens sejam sujeitos ativos nesse processo ainda inicial de definição de políticas nacionais dirigidas aos setores juvenis da população brasileira. É fundamental, portanto, empreender um esforço de compreensão das motivações e percepções dos jovens sobre a participação.

Em relação aos caminhos participativos, os jovens que participaram dos cinco grupos de diálogo formaram um quarto caminho a partir da combinação dos três, escolheram os três numa associação com os problemas ou fizeram algumas combinações de caminhos. Mas a tendência maior foi não escolher um caminho de forma exclusiva, demonstrando, talvez, um entendimento da complexidade das situações que pedem soluções também complexas e coletivas.

Um novo e quarto caminho significa aos jovens assumir um princípio anterior a qualquer ação: o da escolha. Existe uma clara generosidade na fundamentação da escolha, no sentido de que algo precisa ser feito se o governo não faz, ou para chamar atenção do governo. Algo que poderia ser aprofundado a partir dessa constatação é que a dinâmica proposta na metodologia dos GDS, conectando problemas em relação a temas (educação, trabalho e cultura/lazer) com caminhos participativos (um, dois e três e quatro), de alguma forma revela a «sensibilidade» também do «lado» de quem propôs essa estratégia, pois sem ser «prescritiva» ela se tornou «acolhedora» das narrativas dos jovens.

Pra mim o dia hoje foi importante porque eu pude botar as minhas idéias, e alguém escutou. 
Pra mim foi muito produtivo esse dia de hoje porque eu pude propor minhas idéias e ouvir as dos outros e acho que o meu desejo é o mesmo de todo mundo, que o país mude, que o governo mude e que ele tome uma solução, né, porque a gente não guenta mais, tá todo mundo sufocado, é passagem, é tudo, ninguém guenta mais, né.

Eu achei que foi muito legal sabe, porque a gente tem sempre essas idéias. Isso passa pela cabeça da gente, mas... nunca pensei que a gente ia ter oportunidade de falar o que a gente sente, se abrir assim, sabe, poder... bah, foi muito legal, sabe.

As conclusões dos jovens pesquisados da RMPA situam-se no contexto de um país que tem um número expressivo de jovens sem um conjunto mínimo de direitos que lhes permita viver a juventude e ter acesso aos bens culturais, à educação, ao trabalho e ao tempo livre. Os jovens como sujeitos de direitos no campo das políticas públicas indicam uma demanda mais centrada na «garantia» do acesso à educação, ao trabalho e à cultura e lazer.

Reconhecendo a diversidade dos coletivos juvenis, torna-se necessário considerar que desenhos institucionais poderão romper com as estruturas burocráticas e tradicionais que concebem o jovem como problema social para, em outra via, considerá-los como sujeito de direitos.

Nesta parte final do texto, retornamos ao tema principal da pesquisa - participação - com referência aos estudos sobre juventude que apontam que os conteúdos da participação social estão voltados para temas como democracia, direitos sexuais, eqüidade de gêneros, direitos humanos, direitos indígenas, paz e meio ambiente. Este último representa um tema fundamental, que tem gerado um novo ator social, pois a destruição do meio ambiente é uma luta que incorpora diferentes setores e classes com uma capacidade de ação em torno de assuntos concretos em âmbito local, ao mesmo tempo em que se estabelecem redes e condenações nacionais e internacionais.

Serna (1997) afirma que é justamente essa uma característica da participação juvenil hoje em dia: a diversidade e a dispersão dos conteúdos e das formas de atuar, entendendo a participação juvenil como um processo em constante movimento, pois os grupos, redes, movimentos, organizações nascem e morrem, renascem com novos nomes e propostas e esse contínuo recriar parece ir construindo os jovens como atores sociais. Para além de uma «disposição sem engajamento», revelada pelas pesquisas quantitativas, há muitos jovens que par- 
ticipam efetivamente. Talvez devêssemos construir novas perguntas e novos olhares, para perceber a existência de diferentes formas de mobilização entre os jovens que, segundo Abramo (2004),

Vão desde a recusa passiva-postura que, mais que uma manifestação de apatia, contém a emissão de recados críticos à sociedade (que também pode ser interpretada como impugnação, como repulsa a um sistema do qual se sentem excluídos), até uma participação política que propõe mudanças (em movimentos estruturados, partidos, sindicatos etc.), passando pela participação individual ou grupal em organizações comunitárias, ou em torno dos mais diferentes tipos de causas, que podem ir das mais locais às mais planetárias, como voluntários em distintos tipos de atividades organizadas por diferentes tipos de instituições, participação em movimentos informais dos mais distintos tipos, em grupos de lazer, em movimentos culturais, em «tribos», assim também, como já citamos, em formas violentas e destrutivas com relação a ordem e segurança social, como no caso das pandillas e algumas torcidas organizadas de esporte.

Por fim, se pensarmos que a participação juvenil hoje é plural, dispersa e fragmentada; que possui uma capacidade de ação relacionada a um assunto concreto; que não é institucionalizada, e é formada por redes vinculantes e flexíveis, que políticas públicas poderão situar os jovens como sujeitos de direito? Pensar políticas públicas de juventude é promover um desenvolvimento social que assegure a justiça social e uma esfera pública democrática.

Os jovens desta pesquisa apontam alguns caminhos, quando anunciam que as questões da sobrevivência são fundamentais para que possam realizar projetos de vida que incluam a participação e a luta pela construção de um Brasil melhor. O que mais os sensibiliza para a participação é o trabalho voluntário, que inicia como uma atitude individual e, de acordo com eles, pode ir se ampliando até influenciar a comunidade e o poder público. Importante salientar ainda que em nenhum momento esses jovens excluem a importância do poder público, tanto em relação à segurança, educação, melhores salários e condições de trabalho como nas ofertas de atividades de cultura e lazer.

PORTO ALEGRE (BRASIL), JUNIO 2006

RECIBIDO: JUNIO 2006

ACEPTADO: SEPTIEMBRE 2006 


\section{REFERENCIAS BIBLIOGRÁFICAS}

ABRAMO, HelENA (2004): «Jovens e juventude: contribuições-participação e organizações juvenis». In: www.iets.org.br.

ABRANTES, PEDRO (2003): «Identidades juvenis e dinâmicas de escolaridade». Sociologia políticas e práticas $\mathrm{N}^{\circ} 41$.

Freire, PAUlo (1997): Pedagogia da autonomia: saberes necessários à prática educativa. São Paulo: Paz e Terra.

DAYRELL, JUAREZ (1996): «A escola como espaço sócio-cultural». In JUAREZ DAYRELL (org.): Múltiplos olhares sobre a educação e cultura. Belo Horizonte: Editora da UFMG.

IBASE/Polis (2005a): «Que Brasil queremos? Como chegar lá? Roteiro para o diálogo da pesquisa juventude brasileira e democracia». Rio de Janeiro: IBASE.

(2005b): «Guia do(a) facilitador(a)». Rio de Janeiro: IBASE.

(2005c): Juventude brasileira e democracia: participação, esferas e políticas públicas. Relatório final. Rio de Janeiro: IBASE.

— (2005d): Juventude brasileira e democracia: participação, esferas e políticas públicas. Relatório da Região Metropolitana de Porto Alegre. Rio de Janeiro: IBASE.

ISLAS, JosÉ ANTONIO PÉREZ (2001): «Pro(Diá)logo, políticas de juventud del nuevo siglo: para mirar lo que vemos». Jóvenes $\mathrm{N}^{\circ} 11$. México: Instituto Mexicano de la Juventud.

Melucci, Alberto (2004): O jogo do eu. A mudança de si em uma sociedade global. São Leopoldo: Unisinos.

- (2001): A invenção do presente. Movimentos sociais nas sociedades complexas. Petrópolis: Vozes.

_ (1994): «Movimentos sociais, renovação cultural e o papel do conhecimento: entrevista com Leonardo Avritzer e Timo Lyra». Novos Estudos CEBRAP v. 40. São Paulo: CEBRAP.

MisCHE, ANN (1997): «De estudantes a cidadãos: redes de jovens e participação política». Revista Brasileira de Educação N5/6. São Paulo: ANPED.

SAlvA, SuEli (2006): «As vozes juvenis acerca da cultura e lazer». Anais do VI Seminário de Pesquisa em Educação da Região Sul e III Seminário dos Secretários dos Programas de Pós-Graduação em Educação. Universidade Federal de Santa Maria, Rio Grande do Sul, Brasil, 07 a 09 de junho.

STECANELA, NiLDA (2006): «Os sentidos da escola para jovens da Região Metropolitana de Porto Alegre: a arte da escuta em grupos de diálogo». Anais do VI Seminário de Pesquisa em Educação da Região Sul e III Seminário dos Secretários dos Programas de Pós-Graduação em Educação. Universidade Federal de Santa Maria, Rio Grande do Sul, Brasil, 07 a 09 de junho.

SERNA, LESLIE (1997): «Globalización y participación juvenil». Jóvenes No5. México: Instituto Mexicano de la Juventud. 